\title{
A PRODUÇÃO CIENTÍFICA SOBRE AS DIRETRIZES CURRICULARES PARA A EDUCAÇÃO FÍSICA (DCNEF): DETERMINAÇÕES HISTÓRICAS E IMPLICAÇÕES PARA FORMAÇÃO E INTERVENÇÃO PROFISSIONAL
}

\author{
SCIENTIFIC WORK ABOUT CURRICULUM GUIDELINES FOR PHYSICAL \\ EDUCATION: HISTORICAL DETERMINATIONS AND IMPLICATIONS FOR \\ PROFESSIONAL TRAINING AND INTERVENTION
}

\author{
LA PRODUCCIÓN CIENTIIFICA SOBRE DIRECTRICES CURRICULARES \\ PARA LA EDUCACIÓN FÍSICA (DCNEF): DETERMINACIONES \\ HISTÓRICAS E IMPLICACIONES PARA LA FORMACIÓN E \\ INTERVENCIÓN PROFESIONAL
}

\section{Júlio César Apolinário Maia*, Michele Silva Sacardo*}

Palavras chave: Atividades cientificas e tecnológicas. Currículo. Legislação.

Keywords: Scientific and technical activities. Curriculum. Legislation.

Palabras clave: Actividades cientificas y tecnológicas. Curriculum. Legislación
Resumo: A presente investigação, cuja tipologia por delineamento é designativa de uma Pesquisa Bibliográfica, debruça-se sobre a produção científica relativa às Diretrizes Curriculares para a Educação Física (DCNEF), objetivando apreender as circunstâncias históricas que estruturam o embate existente no campo da formação e, por conseguinte, intervenção profissional nesta área. Utiliza-se a base dados P@rthenon para levantamento da produção e, posteriormente, identifica 23 artigos, publicados em diversificados instantes e periódicos, classificados em três condicionantes: a) Elaboração das DCNEF; b) Resolução CNE/CES n 07/2004; c) Minuta de 2015. O esforço de síntese identifica que passa a existir, entre os dois últimos condicionantes, tanto uma tendência de readequação da divergência de posicionamentos, como também uma lacuna evidenciada na produção científica ante o número restrito de pesquisas que, após a promulgação da Minuta de 2015, vislumbram subterfúgio ao direcionamento dado a formação e intervenção na área desde as duas últimas décadas.

Abstract: This study, whose typology is Bibliographic Research, addresses scientific work related to Curricular Guidelines for Physical Education (known as DCNEF), aiming to apprehend the historical circumstances that structure the debate existing in the training field and, consequently, professional intervention in the area. The survey was conducted on the P@rthenon database and found 23 articles published at various times and journals, which were selected and classified according to three conditions: a) creation of DCNEF; b) CNE/CES Resolution 07/2004; c) 2015 Minute. The synthesis effort finds (1) a tendency to readjust differences in stances between the last two conditions and (2) a gap in scientific work as a result of the low number of studies that after 2015 Minute find deviation regarding the direction given to training and intervention in the area since the last two decades.

Resumen: La presente investigación, cuya tipología por delineamiento es designativa de una Investigación Bibliográfica, explora la producción científica relativa a las DCNEF, objetivando entender las circunstancias históricas que estructuran el embate existente en el campo de la formación y, consecuentemente, intervención profesional en esta área. Se utiliza la base de datos P@arthenon para hacer el levantamiento de la producción y, posteriormente, son identificados 23 artículos, publicados en diversas fechas y periódicos, que son clasificados en tres condicionantes: a) Elaboración de las DCNEF; b) Resolución CNE/CES nº 07/2004; c) Minuta de 2015. El esfuerzo de síntesis identifica que pasa a existir, entre los dos últimos condicionantes, una tendencia de readecuación de la divergencia de posicionamientos, además de constatar una laguna evidenciada en la producción científica, al haber un número restricto de investigaciones que, después de la Minuta de 2015, vislumbran subterfugio a la dirección dada a la formación e intervención en el área en las últimas dos décadas.
*Universidade Federal de Goiás, Regional Jataí. Jataí, GO, Brasil. E-mail:

jcesarm@outlook.com; michelesacardosilva@gmail.com

Recebido em: 22-10-2019 Aprovado em: 09-04-2020 Publicado em: 13-05-2020 (c) (i) (8) Licence 


\section{INTRODUÇÃO}

A previsibilidade de um estudo que busque mapear a produção científica sobre as Diretrizes Curriculares para a Educação Física (doravante DCNEF) no âmbito dos periódicos nacionais deve incorporar, por conveniência, o reconhecimento de que historicamente o campo acadêmico-profissional desta área, fundamentalmente influente à elaboração de suas Diretrizes Curriculares Nacionais (DCN), atrela-se a diferentes áreas do conhecimento. Sobremaneira, é importante compreender que a multidisciplinaridade dada ao campo acadêmico-profissional em Educação Física, como constata ampla maioria dos autores associados à tema, acompanha o desenvolvimento das forças produtivas, caracterizadas enquanto sustentáculo hegemônico do capital (TAFFAREL, 1993; NOZAKI, 2004; SANTOS JÚNIOR, 2005).

Compreender, por conseguinte, as DCNEF como corolário das circunstâncias históricas que estruturam o embate existente nocampo da formação, e porconsequência no campo da intervenção profissional em Educação Física, é pressuposto para uma análise da produção científica sobre o tema das DCNEF. É importante assinalar que ao mesmo tempo em que este embate antecede a proposição das DCNEF, também aponta para a necessidade de sua consolidação, o que vem a ocorrer, enfaticamente, sob a égide da Resolução da Câmara de Educação Superior do Conselho Nacional de Educação (CNE/CES) nº 07/2004 (BRASIL, Parecer, 2004a).

Cabe fazer ressalva, preliminarmente, ao fato de que o primeiro levantamento das produções científicas, alvo da presente investigação, realizou-se por meio da base de dados $\mathrm{P} @$ rthenon, que retorna buscas de conteúdo por meio do portal CAPES e de fontes subscrevidas pela Universidade Estadual Paulista (UNESP). A partir de dois identificadores empregados à busca, "Diretrizes curriculares nacionais" e "Educação Física", o retorno das produções científicas logrou um quantitativo de 197 artigos.

A averiguação de pertinência sobre o material retornado às vias do primeiro levantamento considerou, inicialmente, a análise dos títulos. Neste instante o quantitativo de artigos obteve um decréscimo, alcançando o número de 27 produções.

Posteriormente, no que concerne ainda a averiguação de pertinência da produção científica alçada sobre o tema das DCNEF, já no que diz respeito ao material filtrado a partir da leitura dos títulos, realizou-se nova leitura dos mesmos em conjunto à apreciação dos resumos. O saldo deste segundo instante caracterizou-se pelo quantitativo de 23 artigos, que se vinculam, a partir da categorização apresentada a seguir, a diferentes periódicos científicos, sobre o plano de fundo de distintos determinantes históricos, e a partir de dissemelhantes (e certamente divergentes) pontos de vista de seus autores e coautores. A Tabela 1 apresenta o quantitativo de artigos ao serem levados em consideração, seus respectivos anos e periódicos científicos de publicação. 
Tabela 1 - Artigos distribuídos por revista e por ano.

\begin{tabular}{|c|c|c|c|c|c|c|c|c|c|c|}
\hline \multirow[b]{2}{*}{ REVISTAS } & \multicolumn{9}{|c|}{ ANO } & \multirow[b]{2}{*}{ Total/revista } \\
\hline & 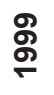 & 옹 & ஜ & $\begin{array}{l}\infty \\
\text { ᄋ̊ } \\
\text { ○्र }\end{array}$ & ז্ণ & $\frac{N}{\text { N }}$ & 뀨 & $\stackrel{\text { * }}{\stackrel{*}{\sim}}$ & $\stackrel{\circ}{\stackrel{\sim}{N}}$ & \\
\hline Educação e Pesquisa & - & - & - & 1 & - & - & - & - & - & 1 \\
\hline Fronteiras & - & - & - & - & - & - & - & & 1 & 1 \\
\hline Kinesis & - & - & - & - & - & 1 & - & - & - & 1 \\
\hline Motrivivência* & 1 & 1 & 1 & - & 1 & 1 & - & 4 & - & 9 \\
\hline Motriz & - & - & - & - & - & 1 & - & - & - & 1 \\
\hline Movimento & - & - & - & - & - & 1 & - & - & & 1 \\
\hline Pensar a prática & - & - & - & - & - & - & - & - & 6 & 6 \\
\hline RBCE & - & - & - & - & - & - & 1 & 1 & - & 2 \\
\hline Revista da Educação Física & - & - & - & - & - & - & - & 1 & - & 1 \\
\hline Total/ano & 1 & 1 & 1 & 1 & 1 & 4 & 1 & 6 & 7 & 23 \\
\hline
\end{tabular}

Fonte: próprios autores, 2019.

Legenda: *Periódico e ano com maior $\mathrm{n}^{\circ}$. de publicações pertinentes aos parâmetros da busca.

Os artigos, dentro da orientação dispostana Tabela 1, podem ser compreendidos com base em uma categorização temporal demarcada por três condicionantes aliados ao período apurado (1999-2016), vide Tabela 2: a) A elaboração DCNEF (1999; $n^{\circ}$ de artigos: 01); b) A Resolução CNE/CES nº 07/2004 (2005-2016; nº de artigos: 16) e; c) A Minuta de nova Resolução das DCNEF (BRASIL, Minuta, 2015) redigida em dezembro de 2015 (2016; $n^{\circ}$ de artigos: 5).

Tabela 2 - Artigos distribuídos por ano e por condicionante

\begin{tabular}{|c|c|c|c|c|}
\hline \multirow{2}{*}{ ANO } & \multicolumn{3}{|c|}{ CONDICIONANTE } & \multirow{2}{*}{$\begin{array}{c}\text { Total } \\
\text { ano }\end{array}$} \\
\hline & Condicionante $01^{*}$ & Condicionante $02^{* *}$ & Condicionante $03^{* * *}$ & \\
\hline 1999 & David et al. & - & - & 1 \\
\hline 2005 & - & Titton, Tranzillo e Alves. & - & 1 \\
\hline 2006 & - & Quelhas e Nozaki. & - & 1 \\
\hline 2008 & - & $\begin{array}{c}\text { Benites, Souza Neto e } \\
\text { Hunger. }\end{array}$ & - & 1 \\
\hline 2011 & - & Sousa Sobrinho. & - & 1 \\
\hline 2012 & - & $\begin{array}{l}\text { Alves; Lemos et al.; Nunes, } \\
\text { Votre e Santos; Taffarel. }\end{array}$ & - & 4 \\
\hline 2013 & - & Veronez et al. & - & 1 \\
\hline 2014 & - & $\begin{array}{l}\text { Almeida e Silva; Alves } \\
\text { e Figueiredo; Marques } \\
\text { e Figueiredo; Pizani e } \\
\text { Barbosa-Rinaldi; Rezer et } \\
\text { al.; Souza, Fuchs e Ramos. }\end{array}$ & - & 6 \\
\hline
\end{tabular}

2016

Oliveira-Silva, Oliveira e Guimarães.
Furtado et al.;

Oliveira e Andrade;

Rodrigues et al.;

Castellani Filho;

Souza Neto et al.

\begin{tabular}{llccc}
\hline $\begin{array}{l}\text { Total/ } \\
\text { condicionante }\end{array}$ & 1 & 16 & 5 & 22 \\
\hline
\end{tabular}


Ao contabilizar os trabalhos dispostos em todos os condicionantes apresentados pela Tabela 2, obtêm-se um quantitativo de 22 artigos. Existe, por conseguinte, um único trabalho - Metzner, Cesana e Drigo (2016) - que não se enquadra em nenhum dos condicionantes destacados, mas que não deixa de compor o quadro, elaborado pelo presente estudo, do conjunto de produções científicas pertinente ao tema das DCNEF. O trabalho em questão não se enquadra em nenhum dos condicionantes por deter-se a uma análise da produção acadêmica e científica do decênio 2006-2016 sobre o tema DCNEF, logo se configura enquanto semelhante esforço de síntese ao aqui pretenso.

A produção relativa ao primeiro condicionante, a exemplo, notabiliza o tema da urgente consolidação das DCNEF. O segundo dispõe-se de artigos que demarcam subtemas desarmônicos, ora caracterizados pelo tema "Crítica à Resolução CNE/ CES n 07/2004", ora pelo tema "Acato à Resolução CNE/CES n 07/2004". Por sua vez, e de forma semelhante ao anterior, o último condicionante trazido à tona pelo presente estudo compreende também artigos dissonantes, caracterizados ora pelo tema "Acato à Minuta de nova Resolução das DCNEF", ora pelo tema de crítica a este documento. O Quadro 1 carrega a correta distribuição de todos os temas e possíveis subtemas enfatizados em cada condicionante.

Quadro 1 - Distribuição de condicionantes de acordo com temas e subtemas.

\begin{tabular}{|c|c|c|}
\hline CONDICIONANTE & TEMA & SUBTEMA \\
\hline Condicionante 1 & Consolidação das DCNEF & - \\
\hline \multirow{5}{*}{ Condicionante 2} & \multirow{4}{*}{$\begin{array}{l}\text { Crítica à Resolução CNE/CES nº } \\
\text { 07/2004. }\end{array}$} & $\begin{array}{c}\text { Posicionamento do Movimento } \\
\text { Estudantil de Educação Física (MEEF) } \\
\text { ante o falso consenso saldado a partir } \\
\text { da proposta de DCNEF. }\end{array}$ \\
\hline & & Reinterpretação das DCN de 2004. \\
\hline & & Defesa da Licenciatura Plena \\
\hline & & $\begin{array}{l}\text { Descompromisso epistemológico da } \\
\text { Educação Física ante a proposta de } \\
\text { DCNEF. }\end{array}$ \\
\hline & $\begin{array}{l}\text { Acato à Resolução CNE/CES nº } \\
\text { 07/2004. }\end{array}$ & $\begin{array}{l}\text { Defesa do campo de atuação do } \\
\text { Bacharelado em Educação Física. }\end{array}$ \\
\hline \multirow{2}{*}{ Condicionante 3} & $\begin{array}{l}\text { Acato à Minuta de nova Resolução } \\
\text { das DCN. }\end{array}$ & - \\
\hline & $\begin{array}{l}\text { Crítica à Minuta de nova Resolução } \\
\text { das DCN. }\end{array}$ & - \\
\hline
\end{tabular}

Fonte: próprios autores, 2019.

A análise que se segue, portanto, vale-se do contexto histórico da formação e intervenção profissional em Educação Física para a adequada compreensão da produção científica sobre o tema das DCNEF.

\section{CONDICIONANTE 1: O TEMA DA CONSOLIDAÇÃO DAS DCNEF}

O tema em questão, referente ao primeiro condicionante característico deste estudo, comporta um único artigo, intitulado "Diretrizes curriculares nacionais para 
o ensino superior: contribuições para o debate em educação física \& esportes". Tal estudo almeja subsidiar, ainda no contexto representativo do fechamento do século passado, a criação das DCN para os cursos de Graduação em "Educação Física e Esportes". Para tanto elabora propostas ao CNE - no tocante aos objetivos de um curso de formação, como também seu perfil profissional, competências, conteúdos curriculares, duração, estruturação modular, flexibilidade, aprofundamento de conhecimentos, monitorias, formação cientifico-cultural e práticas de ensino de estágios - ao mesmo tempo em que reflete sobre os seguintes temas: elaboração de propostas curriculares; paradigmas influentes à formação docente em Educação Física; educação brasileira (DAVID et al., 1999).

O momento de publicação do artigo em questão sucede a aprovação da Lei $n^{\circ}$ 9696/98 (BRASIL, Lei, 1998), que regulamenta ${ }^{1}$ a profissão com base na criação dos Conselhos Profissionais da Educação Física, como também a rediscussão, elaborada por uma Comissão de Especialistas de Ensino em Educação Física (COESP-EF) ligada ao Ministério da Educação, acertada pela Portaria n 972/97 (BRASIL, Portaria, 1997b), das diretrizes para o Bacharelado, estabelecidas uma década antes, em acordo ao recém-instituído Parecer CNE/CES n 776/97 (BRASIL, Parecer, 1997a), que instituía as orientações para as diretrizes curriculares dos cursos de graduação.

O destaque de ambos os documentos é de fundamental importância para compreensão do contexto político-educacional enfrentado por David et al. (1999), que percebendo o conflito existente entre a proposta elaborada pela COESP-EF no ano de 1999 e a possível promulgação de novas DCN para a Formação de Professores da Educação Básica pelo CNE - que efetivamente vem acontecer no ano de 2002 via Resoluções CNE/CP n 01/2002 (BRASIL, Resolução, 2002b) e nº 02/2002 (BRASIL, Resolução, 2002c) -, elaboram um texto contributivo à referida proposta, e sua consequente influência às DCNEF. Tal produção científica é aqui compreendida enquanto peculiar, na particularidade histórica que lhe compreende, sobre o tema das DCNEF.

\section{CONDICIONANTE 2: OS TEMAS DA CRÍTICA E DO ACATO À RESOLUÇÃO CNE/CES N 07/2004}

O tema em questão caracteriza o primeiro grupo de produções relacionadas ao segundo determinante. Nele, os presentes subtemas se expressam: 1)Posicionamento do MEEF ante o falso consenso saldado a partir da proposta de DCNEF ( $n^{\circ}$ de artigos: 1); Reinterpretação das DCNEF de 2004 ( $\left.n^{0}: 3\right)$; Defesa da Licenciatura Plena ( $\left.n^{0}: 1\right)$ e; Descompromisso epistemológico da Educação Física ante a proposta de DCNEF ( $\left.n^{\circ}: 2\right)$. Também se encontra neste grupo algumas produções segundo as quais nenhum subtema pôde ser identificado ( $\left.n^{\circ}: 7\right)$. O Quadro 2, exposto em sequência, permite ampla visualização de todas as produções que compõe este tema.

\footnotetext{
1 A aprovação, no primeiro dia do mês de setembro do ano de 1998, da Lei n 9696/98, que regulamentava a profissão a partir da criação dos conselhos profissionais, foi sancionada pelo presidente da república. Castellani Filho (1998, p. 32), ao escrever sobre "the day after" da aprovação desta lei, assim introduz seu ponto de vista: "A aprovação do PLS n 33/98 [...] foi, ao mesmo tempo, uma demonstração de capacidade de articulação política dos defensores da Regulamentação e outra, inequívoca, de inexistência de ação política concatenada por parte daqueles que a ela se opunham".
} 
Quadro 2 - Distribuição de artigos conforme o tema "Crítica à Resolução CNE/CES n 07/2004" e respectivos subtemas.

\begin{tabular}{|c|c|c|}
\hline TEMA & SUBTEMA & ARTIGO \\
\hline \multirow{4}{*}{$\begin{array}{l}\text { Crítica à Resolução } \\
\text { CNE/CES nº 07/2004. }\end{array}$} & $\begin{array}{l}\text { Posicionamento do Movimento } \\
\text { Estudantil de Educação Física (MEEF) } \\
\text { ante o falso consenso saldado a partir } \\
\text { da proposta de DCNEF. }\end{array}$ & Titton, Tranzillo e Alves (2005). \\
\hline & Reinterpretação das DCN de 2004. & $\begin{array}{c}\text { Alves (2012); Alves e Figueiredo } \\
\text { (2014); Marques e Figueiredo } \\
(2014) .\end{array}$ \\
\hline & Defesa da Licenciatura Plena. & Taffarel (2012) \\
\hline & $\begin{array}{l}\text { Descompromisso epistemológico da } \\
\text { Educação Física ante a proposta de } \\
\text { DCNEF. }\end{array}$ & $\begin{array}{l}\text { Rezer et al. (2014); Souza, Fuchs } \\
\text { e Ramos (2014). }\end{array}$ \\
\hline \multicolumn{3}{|c|}{ ARTIGO SEM IDENTIFICAÇÃO DE SUBTEMA } \\
\hline \multicolumn{3}{|c|}{$\begin{array}{l}\text { Quelhas e Nozaki (2006); Benites, Souza Neto e Hunger (2008); Sousa Sobrinho (2011); Lemos et } \\
\text { al. (2012); Veronez et al. (2013); Almeida e Silva (2014); Oliveira-Silva, Oliveira e Guimarães (2016). }\end{array}$} \\
\hline
\end{tabular}

Fonte: próprios autores, 2019.

Titton, Tranzillo e Alves (2005), primeiro estudo do subtema referente à crítica da Resolução CNE/CES n 07/2004, para além de apresentarem o posicionamento do MEEF ante a Resolução em questão, revelam ser este documento uma manobra de adequação dos professores de Educação Física ao mercado de trabalho contemporâneo, local em que se evidencia a consolidação de projetos de formação conflituosos e, consequentemente, a fragmentação da área. Destarte é da necessidade histórica de reivindicação suplantada sobre a classe trabalhadora que o MEEF se posiciona em desfavor à Resolução CNE/CES n 07/2004, reivindicando um currículo centrado em dois elementos: i) auto-organização estudantil e ii) apreensão de instrumentos de análise da conjuntura, por consequência explicação das contradições e transformação social.

Duas outras produções científicas, sem identificação de subtemas, compartilham do mesmo período histórico, são elas: Quelhas e Nozaki (2006) e Benites, Souza Neto e Hunger (2008). O contexto em que ambos os grupos de autores escrevem compreende ainda um primeiro esforço de interpretação da Resolução CNE/CES n 07/2004.

Quelhas e Nozaki (2006), à procura de nortes que evidenciassem os determinantes consolidativos da promulgação da Resolução CNE/CES nº 07/2004, se propuseram ao resgate do contexto da formação em Educação Física desde a década de 1980. Para além deste anseio se comprometem ainda a apresentar um modelo de formação nesta área respaldado pelas concepções de politecnia e omnilateralidade.

Por outro lado, a linha do tempo traçada por Benites, Souza Neto e Hunger (2008) acha-se no intermédio das proposições da dupla de autores anteriormente analisada, ou seja, o estudo do trio não é tão enfático como o da dupla no que tange à elaboração crítica à formação em Educação Física, mas traz à tona aspectos importantes, decorrentes do histórico processo de transformação desta formação, para o fomento de uma reflexão sobre as Diretrizes de 2004, em especial no referente 
ao excesso de competências técnicas apresentado por estas. Para os autores a configuração adotada pela Resolução CNE/CES n 07/2004 abre brechas para uma formação mista e vazia ou de especialização, arcaica e tecnicista.

Das considerações de ambos os grupos de autores, observa-se, respectivamente pela ordem de análise aqui concebida, processos de retrocesso e inalterabilidade do campo da formação entre o que se propunha a Resolução do antigo Conselho Federal de Educação (CFE) n 03/87 e o que passa a evidenciar a Resolução CNE/CES n 07/2004.

O subtema da Reinterpretação das DCNEF de 2004, no tangente às produções científicas aqui analisadas, manifesta-se, sobretudo, na década ulterior. Sobre este ponto é possível considerar um segundo momento de consequências surtidas em função da estreita investigação deste documento, assim como das respostas aclaradas pelo Parecer CNE/CES n 400/2005 (BRASIL, Parecer, 2005), em consulta acerca da aplicação das DCN para a Formação de Professores da Educação Básica e das DCNEF às diferentes modalidades dos cursos de Graduação em Educação Física. O esforço caracteriza-se pela possibilidade de, dentro das DCNEF em questão, apreender marcos legais às condições de trabalho do Licenciado em espaços distintos da educação básica. Esse pensamento tem respaldo, como anteriormente salientado, no Parecer CNE/CES n 400/2005 e em sua ratificação via Parecer CNE/CES n 255/2012 (BRASIL, Parecer, 2012), e é compartilhado por alguns trabalhos aqui encontrados, a saber: Alves (2012); Alves e Figueiredo (2014); Marques e Figueiredo (2014).

Alves (2012) preocupa-se em demonstrar a multiplicidade de interpretações, adotadas pelos cursos de Educação Física, acerca das DCNEF de 2004. Toma o currículo da Universidade Federal do Sergipe (UFS) como exemplo para evidenciar que o aprofundamento das interpretações deste documento, em contraste ao grande número de análises equívocas acometidas por diversas Instituições de Ensino Superior (IES), é cabal para a correta compreensão da realidade que paira sobre a formação e intervenção do professor de Educação Física.

Similarmente, Alves e Figueiredo (2014) recriminam o modo como o currículo, no seio das discussões e debates acerca da reconfiguração curricular dos cursos superiores em Educação Física, passa a ser tratado a partir da Resolução CNE/CES $n^{\circ} 07 / 2004$. O currículo, ao ver das autoras, têm se tornado massa de manobra às novas alternativas imputadas pelas demandas legais. Ao recriminar tal entendimento dado ao currículo, e valendo-se da proposta curricular do curso de Licenciatura em Educação Física da Escola de Educação Física, Fisioterapia e Terapia Ocupacional (EEFFTO) da Universidade Federal de Minas Gerais (UFMG), ressalvam à urgente necessidade de aprofundamento sobre as múltiplas interpretações acerca das políticas curriculares.

Este posicionamento também é compartilhado pelo estudo de Marques e Figueiredo (2014), ao dedicarem-se à investigação das múltiplas interpretações curriculares das DCNEF e identificarem, a partir destas, o não engessamento dos cursos de Educação Física às orientações legais dispostas naquele documento, uma vez que favorece a permissividade de manobras, omissões e múltiplas interpretações. 
Para além destas três produções científicas, observa-se também o grupo de autores, e consequentemente de produções, que interpretavam as determinações regulatórias dispostas no conjunto de documentos pertinentes às DCNEF a partir da segmentação do campo de atuação profissional na área. Este grupo de autores pode ser enxergado nalgumas produções científicas filtradas pelo presente estudo.

Tal conjunto de produções científicas, com exclusiva finalidade de estabelecer contraposição e crítica à Resolução CNE/CES n 07/2004 e que não esclarecem subtemas, compreende os seguintes artigos: Sousa Sobrinho (2011); Lemos et al. (2012); Veronez et al. (2013); Almeida e Silva (2014); Oliveira-Silva, Oliveira e Guimarães (2016).

Sousa Sobrinho (2011) estabelece crítica a quatro pontos da Resolução CNE/ CES n 07/2004: i) teoria das competências como eixo norteador; ii) concepção de ciência; iii) movimento humano como objeto de estudo e; iv) fragmentação da área. O autor busca deixar evidente, em função destes pontos, a precarização de formação exposta por este documento e cogita a urgência de sua superação.

Lemos et al. (2012), apoiam-se, similarmente, numa análise crítica e retrospectiva das iniciativas para a elaboração das DCNEF desde a década de 1990, constatando que a promulgação destas, via Resolução CNE/CES nº 07/2004, indubitavelmente, corresponde a um projeto hegemônico de formação, ou seja, submissão dos processos de formação humana ao capital. Para estes autores, de forma análoga a crítica estabelecida por Sousa Sobrinho (2011) sobre os quatro pontos, existe um conjunto de ênfases expresso na composição deste documento, que coaduna com o projeto de um bloco hegemônico. São estas as ênfases: a) fragmentação da formação entre licenciatura e bacharelado; b) fragmentação do conhecimento no interior dos cursos; c) negligencia a função social da Educação Física em detrimento à promoção de um estilo de vida ativo e saudável; iv) e ênfase dada ao movimento humano enquanto objetivo desta área.

Em dinâmica semelhante Veronez et al. (2013) analisam o processo de elaboração das DCNEF enquanto fomento às demandas da mundialização do capital, processo característico à década de 1990 que adotou, enquanto objetivo central, intervenção sobre os cursos de formação e profissionalização da classe trabalhadora em prol de uma nova legitimação ideológica dos interesses de classe, sobretudo mercantis e privatistas, dos grupos favorecidos.

A produção de Almeida e Silva (2014) vem somar às argumentações que passam a entender, enquanto resquício primeiro das reuniões que deram origem à Resolução CNE/CES n 07/004, a ideia de "falso consenso" entre o antagonismo dos dois núcleos internos ao campo da Educação Física à época. Para tanto se posicionam contra os setores conservadores e destacam o desfavor, prestado pelo documento em questão, para com a perspectiva de uma Licenciatura Ampliada, na medida em que este mantém expressivo diálogo com os interesses (especialmente pedagógicos) do capital.

Por último, relativo ao conjunto de produções sem identificação de subtemas e pertencentes ao segundo condicionante de estudos destacados neste arrazoado, encontra-se o artigo de Oliveira-Silva, Oliveira e Guimarães (2016). Estes autores 
se comprometem a uma retrospectiva histórica de questões pertinentes às DCNEF. Abordam a gênese da área e buscam deixar claro, em meio ao movimento de consolidação das DCNEF de 2004, o histórico momento de incerteza que assinala o campo da formação relativo ao professor de Educação Física no bojo de um embate travado entre diferentes correntes ideológicas.

Adiante se encontram ainda três estudos característicos a este condicionante. O primeiro deles acha-se vinculado ao subtema que defende a Licenciatura Plena (TAFFAREL, 2012), e os outros dois ao subtema que evidencia o não comprometimento epistemológico acometido à área em função do monopólio posto ao debate sobre as DCNEF de 2004 (REZER et al., 2014; SOUZA, FUCHS e RAMOS, 2014).

Taffarel (2012) dedica-se à denúncia da perspectiva de formação disposta nas Diretrizes de 2004. Faz ressalva, a partir desta denúncia, à atuação do sistema CREF/CONFEF, em conluio ao CNE, na implantação do documento em questão. A partir deste texto a autora, enfaticamente, impõe-se ao debate da formação unificada, levanta a necessidade da crítica às DCNEF de 2004 e formula novas Diretrizes Curriculares visando superar a divisão que protagoniza a formação acadêmica no campo da Educação Física.

O subtema que evidencia o descomprometimento epistemológico acometido à Educação Física em função do monopólio depositado no debate sobre as DCNEF de 2004, por fim, esgota o tema da crítica a este documento. Este subtema, como anteriormente mencionado, pode ser aqui referenciado por duas produções: Rezer et al. (2014) e Souza, Fuchs e Ramos (2014).

A produção de Rezer et al. (2014) protesta contra a perda de tempo, evidenciada durante os últimos anos, para com esforços de reestruturação curricular no campo da Educação Física. Os autores defendem que este tempo teria sido fundamental e precioso para o amadurecimento epistemológico da área. Concordam não haver justificativa plausível para a segmentação da área, portanto compreendem ter sido desnecessário o processo de reformulação curricular, a partir da apresentação de alguns momentos característicos deste processo.

Souza, Fuchs e Ramos (2014), por vez, averiguam as DCNEF a partir de três categorias: legalidade, conhecimento e "mundo/mercado" de trabalho. Enfatizam, a partir do processo de reajuste curricular em prol das demandas do capital - observado a partir da Resolução CNE/CES n 07/2004 -, tanto o descompromisso epistemológico da área, quanto uma submissão profissional à lógica da empregabilidade. Compreendem, tendo transcorrido exatos 10 anos desde a promulgação deste documento, a continuidade de desafios a serem ultrapassados para a consolidação de uma formação em Educação Física sob o ponto de vista da totalidade.

Cabe fazer menção, enquanto estratégia de desfecho deste segundo momento de análise das produções científicas acerca das DCNEF, ao estudo de Furtado et al. (2016), que apesar de se dedicar à defesa da Minuta do Projeto de Resolução das novas DCNEF, último tema a ser demarcado nesta pesquisa, também busca parametrizar alguns acontecimentos históricos pós-DCNEF de 2004, de relevância fundamental para o remate do tema designado ao grupo de produções anteriormente estudado. 
Ao buscarem evidenciar o contexto que substanciava os cursos de graduação em Educação Física no decorrer do pós-promulgação das DCNEF de 2004, Furtado et al. (2016) constatam um comportamento comum aos cursos de Licenciatura em Educação Física: a necessidade de complementação da formação, a partir do Bacharelado, para a viabilização da atuação além do ambiente escolar.

A partir da problematização "[...] epistemologicamente o objeto de estudo do campo é diferente para a Licenciatura e para o Bacharelado?", Furtado et al. (2016, p. 776) desenvolvem uma profunda interpretação acerca da Resolução CNE/ CES n 07/2004. Advém, pois, desta ressalva, a naturalização de um equívoco que, por consequência, torna habitual a segmentação do campo de intervenção entre os Licenciados e Bacharéis na área (FURTADO et al., 2016). Enquanto afirmação de uma posição contrária à naturalização deste equívoco, estes autores munem-se de duas pronúncias do $\mathrm{CNE}$, concebidas tanto em resposta ao hábito de fornecimento de registo tomado pelo sistema CONFEF/CREF, quanto em justificativa à atualização das DCNEF durante o ano de 2011, via Parecer CNE/CES n 274/2011 (BRASIL, Parecer, 2011).

É sobre a orientação destes autores que se projeta a conjuntura demarcada pelas DCNEF a partir da década de 2010, importante para a compreensão tanto da realidade objetiva em que se debruçam as produções científicas vinculadas ao tema anterior, especulativas das DCNEF, quanto daquelas que se debruçam ao novo tema: a Minuta do Projeto de Resolução das novas DCNEF.

Este embaraçoso contexto, característico dos embates ao redor das DCNEF durante a década de 2010, obtém seu auge nos anos de 2014 e 2015. Neste biênio presencia-se, no entorno de um posicionamento por parte do CNE, uma grande quantidade de mobilizações advindas de IES, egressos, docentes, discentes, Universidades, etc. No dia 15 de outubro de 2015, na cidade de Goiânia, realiza-se uma audiência pública onde um conselheiro do CNE noticia o trabalho de revisão das $D \mathrm{DNEF}^{2}$. No mês seguinte nova audiência é realizada, na cidade de Brasília, para se apresentar a Minuta do Projeto de Resolução das novas DCNEF, tema analisado em sequência à apresentação dos dois últimos estudos - Nunes, Votre e Santos (2012); Pizani e Barbosa-Rinaldi (2014) - que compõe o acato à Resolução CNE/CES n 07/2004, passíveis de melhor vislumbre no Quadro 3.

Quadro 3 - Distribuição de artigos conforme o tema "Acato à Resolução CNE/CES n 07/2004".

\begin{tabular}{|c|c|}
\hline TEMA & ARTIGO \\
\hline Acato à Resolução CNE/CES n 07/2004. & $\begin{array}{c}\text { Nunes, Votre e Santos (2012); Pizani e Barbosa- } \\
\text { Rinaldi (2014). }\end{array}$ \\
\hline
\end{tabular}

Fonte: próprios autores, 2019

Ambas as produções, ainda que por meio de objetivos não similares, prestamse favoráveis à formação acadêmica e campo de atuação próprios do Bacharelado em Educação Física. Nunes, Votre e Santos (2012) encontram solo fértil nas DCNEF de 2004 para a reflexão de uma formação acadêmica orientada ao campo de atuação

2 Disponível em: https://www.youtube.com/watch?v=p2qRuNWtjWo. Acesso em: 22 maio 2019. 
do Bacharelado. Evidenciam que os currículos de formação se encontram dirigidos ao contexto escolar e necessitam, por conseguinte, serem repensados. Por outro lado, o debate travado por Pizani e Barbosa-Rinaldi (2014) busca evidenciar, em respaldo aos projetos curriculares dos cursos de Educação Física em Licenciatura e Bacharelado do Estado do Paraná, a identificação de orientações legais para a organização dos eixos norteadores que compõe tanto os currículos dos cursos de Licenciatura, quanto os de Bacharelado, uma vez que, para estes autores, ambos possuem características próprias.

Distante do debate articulado pelo primeiro grupo de autores, em crítica às DCNEF de 2004, as duas últimas produções não só acatam este documento, como também enxergam a necessidade de as IES valerem-se de suas normativas para a contextualização de seus PPC. Também preconizam, às IES que oferecem os cursos de Licenciatura em Educação Física, a necessidade a apreensão das normativas dispostas nas Resoluções CNE/CP n 01/2002 e n 02/2002 para a readequação de seus PPC.

$\mathrm{Na}$ contramão das publicações apresentadas anteriormente, condizentes à crítica das DCNEF de 2004, o cenário que configurava a aflição dos autores vinculados ao tema de acato à Resolução CNE/CES n 07/2004, carecia de cursos de Licenciatura e Bacharelado com identidades próprias, ou seja, adequadas às normativas legais dispostas pelos Pareceres e Resoluções de 2002 e 2004 (BRASIL 2002a, 2002b, 2002c; BRASIL 2004a, 2004b). A este momento cabe, portanto, transpor o direcionamento do presente estudo à análise das produções que características do terceiro condicionante, a Minuta do Projeto de Resolução das novas DCNEF.

\section{CONDICIONANTE 3: OS TEMAS DO ACATO E DA CRÍTICA À MINUTA DO PROJETO DE RESOLUÇÃO DAS NOVAS DCNEF}

Os artigos que caracterizam ambos os temas se empenham em analisar, dentro da particularidade dada aos seus respectivos motes, algumas implicações acometidas pela Minuta do Projeto de Resolução para as novas DCNEF. O primeiro artigo, Furtado et al. (2016), vincula-se ao acato da Minuta em questão, os outros três, Oliveira e Andrade (2016), Rodrigues et al. (2016) e Castellani Filho (2016) prendem-se à crítica. O Quadro 4 aclara esta visualização:

Quadro 4 - Distribuição de artigos conforme os temas "Acato à Minuta do Projeto de Resolução das novas DCNEF" e "Crítica à Minuta do Projeto de Resolução das novas DCNEF".

\begin{tabular}{|c|c|}
\hline TEMA & ARTIGO \\
\hline $\begin{array}{c}\text { Acato à Minuta do Projeto de Resolução das } \\
\text { novas DCNEF. }\end{array}$ & Furtado et al. (2016). \\
\hline $\begin{array}{c}\text { Crítica à Minuta do Projeto de Resolução das } \\
\text { novas DCNEF. }\end{array}$ & $\begin{array}{c}\text { Oliveira e Andrade (2016); Rodrigues et al. } \\
\text { (2016); Castellani Filho (2016). }\end{array}$ \\
\hline \multicolumn{2}{|c|}{ ARTIGO SEM IDENTIFICAÇÃO DE SUBTEMA } \\
\hline \multicolumn{2}{|c|}{ Souza Neto et al. (2016). } \\
\hline \multicolumn{2}{|c|}{}
\end{tabular}


O estudo de Furtado et al. (2016) busca evidenciar, com ênfase dada no contexto das IES da cidade de Goiânia, o processo de instabilidade jurídica propiciado a partir da apresentação da Minuta de do Projeto de Resolução das novas DCNEF. Posicionam-se, estes autores, favoráveis à decisão tomada pelo CNE: a atuação do Licenciado para além da educação básica. Inicialmente confrontam o contrassenso existente na decisão STJ proferida em dezembro de 2014 - conjuntura anteriormente evidenciada neste mesmo estudo. Pontuam, por conseguinte, a extrema necessidade de reversão, pelo CNE, do quadro conjuntural em que se instalam as DCNEF.

Em contraproposta outras três produções podem ser apreciadas: Oliveira e Andrade (2016), Rodrigues et al. (2016) e Castellani Filho (2016). A primeira delas busca apresentar conflitos entre a Minuta em questão e a formação profissional em Educação Física no campo da saúde. Esclarecem os autores que a formação em Educação Física já se encontra deficitária com relação ao setor da saúde, sobretudo no que concernem as demandas do Sistema Único de Saúde, e que a extinção do Bacharelado, como pressupõe o documento elaborado pelo CNE, dificultaria ainda mais a possibilidade deste profissional se articular neste campo. Esclarecem, em consideração, que a formação do Bacharel se configura pressuposto de enfrentamento da Educação Física às dificuldades que se apresentam no setor da saúde.

Rodrigues et al. (2016) analisam, noutra linha de raciocínio, do ponto de vista da qualificação da formação para o magistério na educação básica, se a Minuta em questão, propositora da unificação da formação de professores na área da Educação Física, corrobora para com as DCN para a Formação de Professores. Concluem fazendo menção às contradições existentes entre os dois documentos analisados, ou seja, evidenciando a não paridade entre a Minuta e as DCN para a Formação de Professores.

Partindo-se da Minuta de 2015 Castellani Filho (2016) compreende a eliminação do Bacharel e, por consequência, a margem dada à Licenciatura enquanto única formação - imune e desobrigada de todo e qualquer registro e vínculo para com o sistema CONFEF/CREF -, um completo equívoco. Apesar de não se simpatizar com este sistema, o autor acredita não ser através do combate à formação profissional, desprovido de rigor sobre a qualidade do processo formativo posto à realidade, que este sistema pode ser combatido.

Para Castellani Filho (2016), portanto, a perspectiva de formação a ser defendida é viabilizada conforme a recontextualização do Bacharelado em Educação Física, a partir de toda a atenção voltada a esta formação nos dias atuais, para além do referencial biofisiológico, como também da Licenciatura em Educação Física, a partir de uma exclusividade dada à educação escolar na formação de professores.

Torna-se tão pertinente, em paridade aos objetivos aqui traçados, analisar a produção de Souza Neto et al. (2016), que aqui passa a ser compreendida enquanto um esforço pelo esclarecimento e apreensão dos diferentes agentes que se encontram envolvidos, de alguma forma, ao cenário de estruturação das DCNEF. O esforço destes autores, portanto, não se atém ao acato ou levantamento de críticas sobre a Minuta do Projeto de Resolução das DCNEF, mas ao mapeamento das manifestações - e consequentemente dos agentes manifestantes - que se vinculam a este tema. 
Compreendem a profissionalização do campo da Educação Física enquanto um espaço de disputa travada pelo confronto entre os seguintes grupos: reformadores defensores da formação única; defensores - prezam pela manutenção da formação baseada nas DCNEF de 2004; debatedores - importam-se, demasiadamente, com a necessidade de repensar a formação; mediador - condutor do debate em acordo ao interesse representativo da sociedade.

\section{CONSIDERAÇÕES FINAIS}

O movimento elucidado busca tornar evidente o conjunto da produção científica sobre as DCNEF no decorrer de quase duas décadas. É importante perceber que existe, inicialmente, entre os dois últimos condicionantes, uma tendência de readequação da divergência de posicionamentos. Significa dizer que o grupo crítico as Diretrizes de 2004 enxergou na Minuta uma possibilidade de restituição do prejuízo saldado durante a última década. Em contrapartida o grupo de acato às Diretrizes de 2004 não vislumbrou uma possibilidade de proveito em decorrência da Minuta em questão.

A permanência deste desentendimento, ao longo da última década, é também objeto de vislumbre dos temas e subtemas relativos à produção científica sobre as DCNEF. Ampla parte dos estudos vinculados ao segundo condicionante preconiza o movimento de crítica às Diretrizes de 2004 (87,5\% | 14 estudos em 16). Posicionamento que se mostra inverso no tocante aos estudos vinculados ao terceiro condicionante, ao priorizarem, em ampla maioria (80\% | 4 estudos em 5), crítica à Minuta de Projeto de Resolução das DCNEF.

Em subtemas, como visto, dividem-se os estudos que tecem crítica à Resolução CNE/CES $n^{\circ}$ 07/2004. As reivindicações expostas pelo conjunto da produção científica correspondente a estes subtemas extrapolam os elementos presentes neste documento, uma vez que se debruçam sobre o resultado dado ao direcionamento histórico concernente à Educação Física. Estes estudos, portanto, entendem as Diretrizes de 2004 como o suprassumo de um projeto de formação em Educação Física que, resguardado por políticas educacionais atinentes aos interesses neoliberais, vem se estruturando desde a década de 1990, mediante o processo de reestruturação produtiva do capitalismo, e suas consequentes repercussões sobre a qualificação dos trabalhadores.

É importante ressaltar que a produção científica não reflete, em menor escala, a omissão de um posicionamento reivindicatório, crítico às Diretrizes de 2004. Deve-se ficar claro que tanto posicionamentos pró, quanto contra a Minuta de nova Resolução das DCNEF, protagonizaram os debates políticos e acadêmicos no campo da Educação Física ${ }^{3}$ durante e após o ano de 2015. A lacuna evidenciada pelo presente estudo, tangencialmente, restringe-se à produção científica, constatando haver um número restrito de pesquisas que, após a promulgação da Minuta de 2015, vislumbram subterfúgio ao direcionamento dado ao campo da formação e intervenção em Educação Física desde as duas últimas décadas.

3 Basta verificar o estudo de Souza et al. (2016) anteriormente analisado. Os autores se dedicam a verificar as diferentes manifestações sobre o tema da Minuta do Projeto de Resolução para as novas DCNEF. 


\section{REFERÊNCIAS}

ALMEIDA, Ediberto Ferreira de; SILVA, William José Lordelo. Contribuição à crítica da formação de professores de educação física: em defesa da licenciatura ampliada. Motrivicência, v. 26, n. 43, p. 104-117, dez. 2014.

ALVES, Cláudia Aleixo; FIGUEIREDO, Zenólia Christina Campos. Diretrizes curriculares para a formação em educação física: camisa de força para os currículos de formação? Motrivivência, v. 26, n. 43, p. 44-54, dez. 2014.

ALVES, Melina Silva. As falsas interpretações das diretrizes curriculares para a educação física e suas expressões em reformulações curriculares. Motrivivência, v. 24, n. 38, p. 217230, jun. 2012.

BENITES, Larissa Cerignoni; SOUZA NETO, Samuel de; HUNGER, Dagmar. O processo de constituição histórica das diretrizes curriculares na formação de professores de educação física. Educação e Pesquisa, v. 34, n. 2, p. 343-360, maio/ago. 2008.

BRASIL. Lei n 9696/98, de 01 de setembro de 1998. Dispõe sobre a regulamentação da profissão de educação física e cria os respectivos conselho federal e conselhos regionais de educação física. Diário Oficial da União, Brasília, 1998. Disponível em: http://www.planalto. gov.br/ccivil 03/leis//9696.htm. Acesso em: 15 maio 2019.

BRASIL. Minuta de Projeto de Resolução para audiência pública de 11/12/2015. Institui Diretrizes Curriculares Nacionais para o curso de graduação em Educação Física, Licenciatura. Brasília, 2015. Disponível em: http://www.cbce.org.br/upload/bibliotecal Proposta\%20de\%20Resolução DCN\%20Educação\%20Física\%20licenciatura.pdf. Acesso em: 15 maio 2019.

BRASIL. Parecer CNE/CES n 776, de 03 de dezembro de 1997. Orientação para as diretrizes curriculares dos cursos de graduação. Brasília, 1997a. Disponível em: http:// portal.mec.gov.br/cne/arquivos/pdf/CES0776.pdf. Acesso em: 15 maio 2019.

BRASIL. Parecer CNE/CES n 138, de 03 de abril de 2002. Diretrizes Curriculares do Curso de Graduação em Educação Física. Brasília, 2002a. Disponível em: http://portal.mec. gov.br/sesu/arquivos/pdf/13802EdFisica.pdf. Acesso em: 15 maio 2019.

BRASIL. Parecer CNE/CES n 058, de 18 de fevereiro de 2004. Diretrizes Curriculares Nacionais para os cursos de graduação em Educação Física. Brasília, 2004a. Disponível em: http://portal.mec.gov.br/cne/arquivos/pdf/2007/pces058 04.pdf. Acesso em: 15 maio 2019.

BRASIL. Parecer CNE/CES n ${ }^{\circ}$ 400, de 24 de novembro de 2005. Consulta sobre a aplicação das Diretrizes Curriculares Nacionais para a Formação de Professores da Educação Básica e das Diretrizes Curriculares Nacionais para os cursos de graduação em Educação Física ao curso de Educação Física (licenciatura), tendo em vista a Resolução CONFEF no 94/2005. Brasília, 2005. Disponível em: http://portal.mec.gov.br/cne/arquivos/ pdf/pces0400_05.pdf. Acesso em: 16 maio 2019.

BRASIL. Parecer CNE/CES n 274, de 06 de julho de 2011. Indicação referente à revisão do texto das Diretrizes Curriculares Nacionais para curso de Graduação em Educação Física. Brasília, 2011. Disponível em: <http://portal.mec.gov.br/index.php?option=com docman\&view=download\&alias=8772-pces274-pdf\&category_slug=setembro-2011pdf\&ltemid=30192>. Acesso em: 16 maio 2019. 
BRASIL. Parecer CNE/CES n 255, de 06 de junho de 2012. Reexame do Parecer CNE/CES n 400/2005, que trata de consulta sobre a aplicação das Diretrizes Curriculares Nacionais para a Formação de Professores da Educação Básica e das Diretrizes Curriculares Nacionais para os cursos de graduação em Educação Física ao curso de Educação Física (licenciatura), tendo em vista a Resolução CONFEF n ${ }^{\circ}$ 94/2005. Brasília, 2012. Disponível em: http://portal.mec.gov.br/index.php?option=com docman\&view=download\&alias=11551-pces255-12-pdf\&category slug=setembro-2012pdf\&ltemid=30192. Acesso em: 16 maio 2019.

BRASIL. Portaria $n^{\circ}$ 972, de 22 de agosto de 1997. Trata das atribuições e critérios de composição da Comissão de Especialistas da SESu/MEC. Brasília, 1997b. Disponível em: http://portal.mec.gov.br/sesu/arquivos/pdf/Portaria972.pdf. Acesso em: 15 maio 2019.

BRASIL. Resolução CNE/CP n 01, de 18 de fevereiro de 2002. Institui as Diretrizes Curriculares Nacionais para a Formação de Professores da Educação Básica, em nível superior, curso de licenciatura, de graduação plena. Brasília, 2002b. Disponível em: http:// portal.mec.gov.br/cne/arquivos/pdf/rcp01 02.pdf. Acesso em: 15 maio 2019.

BRASIL. Resolução CNE/CP n 02, de 19 de fevereiro de 2002. Institui a duração e a carga horária dos cursos de licenciatura, de graduação plena, de formação de professores da Educação Básica em nível superior. Brasília, 2002c. Disponível em: http://portal.mec.gov. br/cne/arquivos/pdf/CP022002.pdf. Acesso em: 15 maio 2019.

BRASIL. Resolução CNE/CES n 07, de 31 de março de 2004. Institui as Diretrizes Curriculares Nacionais para os cursos de graduação em Educação Física, em nível superior de graduação plena. Brasília, 2004b. Disponível em: http://portal.mec.gov.br/cne/arquivos/ pdf/ces0704edfisica.pdf. Acesso em: 15 maio 2019.

CASTELLANI FILHO, Lino. A formação sitiada. Diretrizes curriculares de educação física em disputa: jogo jogado? Pensar a Prática, v. 19, n. 4, p. 758-773, out./dez. 2016.

CASTELLANI FILHO, Lino. Regulamentação da profissão: the day after "2". Revista Brasileira de Ciências do Esporte, v. 20, n. 2, p. 32-36, set. 1998.

DAVID, Nivaldo Antônio; MASCARENHAS, Fernando; MARCHI, Francisco Luiz de; CERQUEIRA, Márcio Vinícios; CORDIRO JUNIOR, Orozimbo. Diretrizes curriculares nacionais para o ensino superior: contribuições para o debate em educação física \& esportes. Motrivivência, v. 11, n. 12, p. 145-160, mai. 1999.

FURTADO, Roberto Pereira; VENTURA, Paulo Roberto Veloso; ANES, Rodrigo Roncato Marques; PEDROZA, Reigler Siqueira; FERRAZ JÚNIOR, Isaías Moreira. Instabilidade jurídica e outras determinações: o CNE e a proposta de novas DCNs para a educação física. Pensar a Prática, v. 19, n. 4, p. 774-787 out./dez. 2016.

LEMOS, Lovane Maria; VERONEZ, Luiz Fernando; MORSCHBACHER, Márcia; BOTH, Vilmar José. As contradições do processo de elaboração das diretrizes curriculares nacionais dos cursos de formação em Educação Física e os movimentos de resistência à submissão ao mercado. Movimento, v. 18, n. 3, p. 27-49, jul./set. 2012.

MARQUES, Fabíola Borel; FIGUEIREDO, Zenólia Christina Campos. Diretrizes curriculares nacionais e suas repercussões nos currículos de formação docente em educação física. Motrivivência, v. 26, n. 43, p. 30-43, dez. 2014.

METZNER, Andreia Cristina; CESANA, Juliana; DRIGO, Alexandre Jonotta. Diretrizes curriculares nacionais e a educação física: levantamento das produções acadêmicas e científicas dos últimos 10 anos. Pensar a Prática, v. 19, n. 4, p. 747-757, out./dez. 2016. 
NOZAKI, Hajime Takeuchi. Educação Física e reordenamento no mundo do trabalho: mediação da regulamentação da profissão. Tese (Doutorado em Educação) - Campinas: Universidade Federal Fluminense - Faculdade de Educação, UFF/FE, 2004.

NUNES, Marcello Pereira; VOTRE, Sebastião Josué; SANTOS, Wagner dos. O profissional em educação física no brasil: desafios e perspectivas no mundo do trabalho. Motriz, v. 18, n. 2, p. 280-290, abr./jun. 2012.

OLIVEIRA, Rogério Cruz; ANDRADE, Douglas Roque. Formação profissional em educação física para o setor da saúde e as diretrizes curriculares nacionais. Pensar a Prática, v. 19, n. 4, p. 721-733, out./dez. 2016.

OLIVEIRA-SILVA, Iransé; OLIVEIRA, Ricardo Jacó de; GUIMARÃES, Juracy da Silva. Diretrizes curriculares nacionais: qual o caminho para educação física?. Fronteiras: Journal of Social, Technological and Environmental Science, v. 5, n. 3, p. 271-278, dez. 2016.

PIZANI, Juliana; BARBOSA-RINALDI, leda Parra. Organização curricular dos cursos de educação física no paraná: características da licenciatura e do bacharelado. Revista da Educação Física/UEM, v. 25, n. 1, p. 95-108, jan./abr. 2014.

QUELHAS, Álvaro de Azeredo; NOZAKI, Hajime Takeuchi. A formação do professor de educação física e as novas diretrizes curriculares frente aos avanços do capital.

Motrivivência, v. 23, n. 26, p. 69-87, jun. 2006.

REZER, Ricardo; RODRIGUES, Lilian Beatriz Schwinn; SÁ, Clodoaldo Antonio de; REZER, Carla dos Reis; MATIELLO, Marizete Lemes da Silva; ROCHA, Deizi Domingues; STANGA, Adriani Cristiani; KLEINUBING, Neusa Dendena; DUTRA, Altamir Trevisan. As diretrizes curriculares nacionais: desdobramentos para a formação inicial em educação física - ou, por que avançamos tão pouco?. Revista Brasileira de Ciências do Esporte, v. 36, n. 2, supl., p. S472-S485, abr./jun. 2014.

RODRIGUES, Anegleyce Teodoro; SILVA, Adriane Corrêa da; BOSSLE, Fabiano; GARIGLIO, José Angelo; NEIRA, Marcos Garcia; ALVIANO JÚNIOR, Wilson. Análise da minuta de projeto de resolução de diretrizes curriculares nacionais para o curso de educação física e a questão da formação para a docência na educação básica. Pensar a Prática, v. 19, n. 4, p. 711-720, out./dez. 2016.

SANTOS JÚNIOR, Cláudio de Lira. A formação de professores em educação física: a mediação dos parâmetros teórico-metodológicos. Tese (Doutorado em Educação). Salvador: Universidade Federal da Bahia - Faculdade de Educação, UFBA/FACED, 2005.

SOUZA, Maristela da Silva; FUCHS, Marcius Minervini; RAMOS, Fabrício Krusche. Diretrizes curriculares nacionais e o processo de formação de professores em educação física: análise a partir da legalidade, conhecimento e mundo/mercado de trabalho.

Motrivivência, v. 26, n. 43, p. 17-29, dez. 2014.

SOUSA SOBRINHO, José Pereira. Formação de professores na sociedade do capital: uma análise crítica das diretrizes curriculares nacionais para os cursos superiores de educação física. Motrivivência, v. 23, n. 36, p. 129-148, jun. 2011.

SOUZA NETO, Samuel; RUFINO, Luiz Gustavo Bonatto; RODRIGUES, Heitor de Andrade; FONSECA, Rubiane. Conflitos e tensões nas diretrizes curriculares de educação física: o campo profissional como um espaço de lutas e disputas. Pensar a Prática, v. 19, n. 4, p. 734-746, out./dez. 2016. 
TAFFAREL, Celi Nelza Zülke. A formação do profissional da educação: o processo de trabalho pedagógico e o trato com o conhecimento no curso de educação física. Tese (Doutorado em Educação). Campinas: Universidade Estadual de Campinas - Faculdade de Educação, UNICAMP/FE, 1993.

TAFFAREL, Celi Nelza Zülke. Formação de professores de educação física: diretrizes para a formação unificada. Kinesis, v. 30, n. 1, p. 95-133, jan./jun. 2012.

TITTON, Mauro; TRANZILO, Paulo José Riela; ALVES, Melina Silva. O embate de projetos na definição das diretrizes curriculares nacionais dos cursos de educação física: contribuições do meef para formação de professores. Motrivivência, v. 17, n. 2, p. 79-102, dez. 2005.

VERONEZ, Luiz Fernando Camargo; LEMOS, Lovane Maria; MORSCHBACHER, Márcia; BOTH, Vilmar José. Diretrizes curriculares da educação física: reformismo e subordinação ao mercado no processo de formação. Revista Brasileira de Ciências do Esporte, v. 35, n. 4, p. 809-823, out./dez. 2013.

\section{Apoio:}

Coordenação de Aperfeiçoamento de Pessoal de Nível Superior - Brasil (CAPES) Código de Financiamento 001. 